\title{
Recent Advances in Indoor Chemistry
}

\author{
Glenn Morrison ${ }^{1}$
}

Published online: 7 April 2015

(C) Springer International Publishing AG 2015

\begin{abstract}
Just as the chemistry creates urban smog and aerosols that influence climate change, chemistry in building air can alter the indoor environment for better or worse. This review focuses on chemical pathways initiated by oxidants that infiltrate from outdoor air and other indoor-sourced reactants and surfaces that make these environments unique chemical reactors. Ozone reacts with fragrance molecules, tobacco smoke residues, and even human skin oils to generate a host of oxidized organic compounds, secondary organic aerosols, and irritants. Nitrous acid is formed on indoor surfaces and is subsequently cleaved by even the relatively dim light indoor. This raises the indoor concentration of the highly reactive hydroxyl radical. Nitrous acid can also react with tobacco smoke residue to form carcinogenic nitrosamines. Some seek to harness this chemistry to help reduce indoor concentrations of unwanted indoor pollutants using novel surface coatings, but controlling that chemistry is challenging.
\end{abstract}

Keywords Indoor air quality · Chemistry · Ozone · Terpenes . Secondary organic aerosols $\cdot$ Building surfaces

\section{Introduction}

Any discussion of sustainable building environments must include the health, welfare, and productivity of the occupants,

This article is part of the Topical Collection on Built Environment

Glenn Morrison

gcm@mst.edu

1 Missouri University of Science \& Technology, 221 Butler Carlton Hall, Rolla, MO 65409, USA for without that buildings are fundamentally flawed. Indoor air quality and the chemistry that takes place in buildings affect occupants in ways that are still poorly understood. This paper reviews the more recent advances in our understanding of what chemistry occurs and touches on how this chemistry could affect occupants. This review distinguishes between "chemicals" and "chemistry." Chemicals that are simply released or drawn into indoor environments but do not take part in chemical transformations are not included.

Indoor chemistry has been the subject of scientific investigations for several decades, but these have been relatively sparse compared with the thousands of studies on outdoor air chemistry. In his review of 20 years of research, Weschler [1] identified only about 270 indoor chemistry publications between 1991 and 2010. However, as Weschler points out, the much more intensive study of ambient air chemistry has informed our understanding of indoor chemistry. Therefore, a much richer set of resources is available to guide targeted research in indoor environments.

All chemical reactions occurring in the outdoor atmosphere are possible indoors. However, key differences in conditions alter the extent to which these reactions can occur in buildings. Much outdoor chemistry is driven directly by photolytic energy of the sun. Although sunlight through windows can initiate chemistry, indoor environments are dimmer. Compared with the outdoor atmosphere, there is much more surface area available indoors to support interfacial chemistry. Air exchanges within hours in a building, rather than the day or weeks that some species can spend in the atmosphere. Finally, the indoor and outdoor concentrations of many organic and inorganic species differ by one or more orders of magnitude. Taken together, the composition of indoor air can be very different. Combined with the fact that people spend so much more time in buildings than outside, the impact of indoor chemistry on health and welfare is of concern. 
This brief review will focus on results of the past 510 years. There have been several reviews of indoor chemistry in recent years, including the exceptional overview by Weschler in 2011 [1]. I hope that this paper serves to enrich this prior literature without unnecessarily repeating what has already been reported in previous reviews. However, to put recent research in context, it will be necessary to highlight key research from the past.

\section{Ozone and Related Chemistry in Air}

In the context of urban smog, ozone $\left(\mathrm{O}_{3}\right)$ chemistry has been studied extensively since the 1950s. Ozone is formed in a photocatalytic reaction involving sunlight, nitrogen oxides, and organic compounds. During the daytime, ozone is typically present at air concentrations in the tens of parts per billion but can exceed $100 \mathrm{ppb}$ in particularly polluted urban areas. Ozone is highly reactive and will oxidize unsaturated organic compounds to form a large number of products including stable carbonyls such as formaldehyde, short-lived oxidized organic species, highly reactive free radicals, and even aersols (i.e., secondary organic aerosols). Ozone also reacts with nitrogen oxides, unsaturated organic compounds, and other species. Some radical products of these reactions can further react with organics and inorganics to produce further generations of oxidation products. The full picture is highly complex and worthy of over half a century of intensive research. The next step was to apply this knowledge to indoor environments.
In 1993, Nazaroff and Cass [2] developed a mass balance model of indoor air that included chemistry and concluded that much of the chemistry happening outdoor could occur indoors at relevant rates. Weschler and Shields [3] then showed that ozone will react with terpenes at substantial rates in indoor environments. Since that time, ozone and its reactions with terpenes have been among the most well-studied chemistry in the context of indoor air. Some terpenes exist at much higher concentrations indoors because they are emitted by wood, cleaners, air fresheners, and personal care products [4-6]. Interest in better understanding this chemistry in indoor environments led to kinetic studies of ozone-terpene reactions specifically relevant to indoor environments (e.g., $\alpha$-terpineol [7]), observation of secondary organic aerosol formation in lab and field studies [3, 8], and identification of formaldehyde and other undesirable gas-phase products [9]. Rosignol et al. have recently reported field measurements of 35 distinct chemical products of these reactions using modern concentration and derivatization methods [10].

Our current understanding of how this research translates to indoor environments has accelerated in recent years. A central idea is emerging that the outcomes of indoor chemistry are highly dependent on conditions. Building environments are highly heterogeneous: one home is not like the next, and the range of variability in compound concentrations, temperature, relative humidity, and air exchange is wide. Combined with the large number of reactants, products, secondary reactants, and side reactions (Fig. 1), each microenvironment has a unique chemical signature. On the shoulders of early models and experimental research, contemporary chemical models, lab studies, and field research are revealing novel insights.
Fig. 1 Major reactants, products, and pathways of indoor chemistry

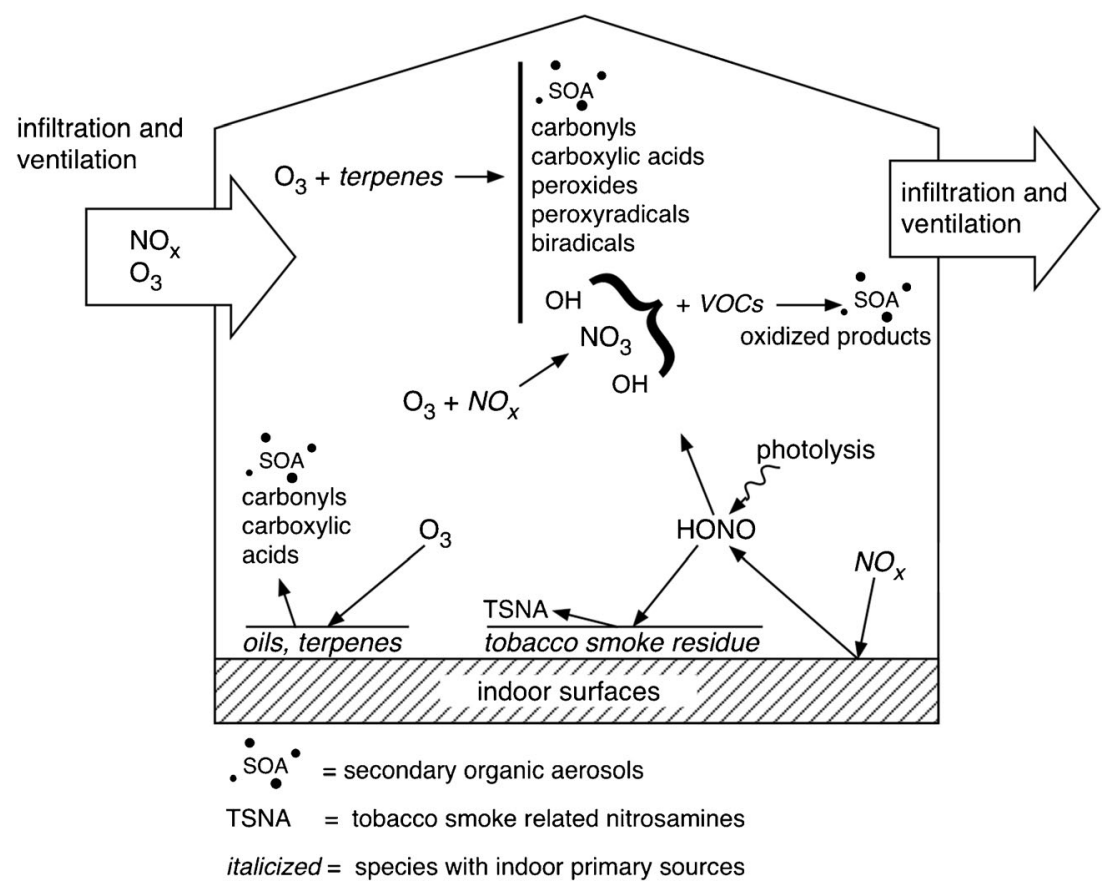


The objective of models of indoor chemistry is to predicting yields of health-related products such as peroxides, irritants, and aerosols. One of the key findings has been that such chemistry is very sensitive to conditions that vary widely among indoor environments. The initial concentrations of ozone, nitrogen oxides, terpenes, other organics, light intensity, and spectral detail strongly influence the outcomes. Carslaw et al. updated a previous model to include identification of over 140 explicit species, radicals, and secondary aerosol formation [11, 12•]. In 2013, Carslaw applied that model to follow limonene oxidation pathways in detail during simulated cleaning activities [13]. The model predicts that carbonyls and peroxyacetyl nitrates are the most common gas-phase species formed. In aerosols, peroxides, carbonyls, and organic nitrates dominate. At higher ozone concentrations, organic acids and alcohols begin to become important in the gas phase, reflecting a shift towards more ozone-dominated oxidation, relative to $\mathrm{OH}$ radical oxidation. Youssefi and Waring modeled secondary organic aerosol (SOA) formation and found that yield is likely to be highly variable indoors and sensitive to ozone and background organic aerosol concentrations [14].

Measurements bear out the general theme that initial conditions significantly influence outcomes. Water (humidity) and nitrogen oxides have been found to influence the production of SOA $[15,16]$. Initial ozone and terpenoid concentrations influence the number and mass concentrations of SOA formed [17]. Pathak et al. found that including an organic compound that scavenged $\mathrm{OH}$ created conditions such that the volatility of SOA was influenced by ozone concentrations [18]. In indoor environments, there are many VOCs other than terpenes that can act to scavenge $\mathrm{OH}$. Ammonia, emitted from sources as diverse as cat litter boxes and cleaners, can also influence SOA generation. Organic acids generated by ozoneterpene chemistry can combine with ammonia to grow or nucleate SOA [19]. However, this sensitivity to initial conditions is not true of all chemical outcomes. In ozone reactions with terpene mixtures, Forester and Wells [20] did not observe any influence of humidity on the yield of hydroxyl radicals.

\section{Surface Chemistry}

Surfaces in buildings can increase apparent rates of reactions, provide unique environments for reactions to take place, and increase the interaction time between chemical reactants [21]. The surfaces are not simply the polyvinylchloride of some flooring, wood, nylon, or brick. All of these unique materials are also coated in adsorbed molecules and/or rather thickly coated in films comprised of high-molecular-weight organics (e.g., oils), salts, water, and numerous other contaminants. Contemporary studies have focused on reactions with (or influenced by) the base materials, coatings, and adsorbed molecules.

Base materials as diverse as brick, wood, carpet, and clothing have all been evaluated for their ability to remove ozone and potential to generate volatile by-products. In general, inorganic substrates tend to remove ozone without byproducts and the ozone removal rate tends to increase with available surface area. Organic or polymer-based substrates have tended to generate more volatile carbonyl byproducts, but this may be due to more oily coatings than to low-reactivity polymers that make up the substrate.

For example, Coleman et al. found that clothing is a source of ozone-generated secondary carbonyl emissions, likely due to reactions with fatty acids and skin oils [22]. More recently, Rai et al. observed similar carbonyl products in ozone-initiated surface chemistry with cotton t-shirts previously worn by subjects [23]. They also observed higher secondary emissions at higher relative humidity.

Many studies have shown that molecules adsorbed to aerosol surfaces can react with ozone at rates that exceed those for the gas-phase reactions (e.g., benzo[a]pyrene and ozone [24]). The rate at which molecules can react indoors overall can also be enhanced at surfaces. On glass and PVC surfaces, $\Delta^{3}$ carene and limonene react with ozone 10-100 times faster than in the gas phase [25]. For lower volatility terpenoids such as $\alpha$-terpineol and dihydromyrcenol, higher adsorbed mass combined with higher relative reaction rates mean that more of these species become oxidized by surface chemistry than by gas-phase chemistry [26, 27]. Further, the yield of reaction products can differ from the gas-phase reaction [28]. Looking beyond individual molecules to mixtures, Destaillats et al. showed that residual compounds left on surfaces after cleaning would increase ozone surface reactivity and generate gas-phase reaction products [9]. Ozone will also react with tobacco smoke residuals on indoor surfaces and generate volatile products such as cotinine [29]. A related, important, finding is that HONO will react with tobacco smoke residue on surfaces and produce carcinogenic tobacco-specific nitrosamines [30•].

In addition to volatile by-products, aerosols can also form upon reaction of ozone with reactive species on surfaces [9]. Several recent studies have observed particle generation that results from ozone reacting with specific surface-associated molecules, such as squalene [31], limonene [32], and nicotine [30•, 33], or with clothing [34] and HVAC filters [35]. In general, the particles generated are in the ultrafine size range $(<100 \mathrm{~nm})$. The particles generated are unique to these sources, can increase number concentrations, and therefore could have unique health consequences. In recent field studies, Reche et al. measured ultrafine particles indoors and outdoors [36]. They suggested that some sources could be surface-mediated production of ultrafine particles because 
indoor/outdoor number concentration ratio of smaller particles was higher at higher outdoor ozone concentrations.

The HONO that was responsible for generating tobaccospecific nitrosamines [30 ${ }^{\bullet}$ can itself be formed at indoor surfaces. HONO is an important compound that "stores" the highly reactive $\mathrm{OH}$ radical. The radical is generated by photolysis of HONO, and this can occur even in the dim light of indoor environments. In 1985, Pitts et al. showed that $\mathrm{NO}_{2}$ can deposit on indoor surfaces and convert to volatile HONO that can generate indoor levels that exceed outdoor levels when NOx is released from gas burners [37]. Several recent studies are demonstrating that HONO formation rates may be enhanced by light. Gomez-Alvarez et al. observed high HONO levels indoors and attributed them to light-induced formation at indoor surfaces [38•]. Later lab studies on painted surfaces and surfaces with cleaner residue observed formation rates that were consistent with field observations $[39,40]$.

\section{Building Characteristics}

Building structure, surfaces, operation, environmental conditions, and so forth can all influence indoor chemistry and the extent to which specific reactions proceed. This increasing understanding of the relationships between building physics and chemistry will be important in controlling chemistry and better understanding population exposure to the results of indoor chemistry.

Several papers have reported on the relationship between building ventilation, recirculation, and filtration on the resulting concentration of ozone, terpenes, and secondary organic aerosols [41-43]. Several general findings have emerged: Increasing exchange of ozone-containing outdoor air (ventilation) increases ozone and increases SOA up to a point, but then SOA decreases with further increases in ventilation; recirculation through particle and/or ozone filters reduces SOA. Use of stand-alone ionizing air cleaners increases indoor ozone and thereby increases terpene oxidation and resulting SOA formation [44].

There has been increasing interest in the use of indoor surfaces, and surface chemistry, as the means to control indoor air pollutants. Typical indoor environments have a large surface area-to-volume ratio and a relatively slow air exchange rate. This means that an indoor gas molecule may strike an indoor surface many thousands, or even millions, of times before being removed by ventilation. Because ozone initiates so many undesirable reactions, it is desirable to identify materials that passively remove ozone without also generating by-products [45]. Activated carbon and clay-based wall coatings appear to be effective at removing ozone [46-48] and can continue to be effective when placed for extended periods in buildings [49]. In a human subject study, Darling et al. found that use of clay-coated panels in a room improved perceived air quality in a chamber with carpet and injected ozone [50]. Only recently have more fundamental studies of relevant materials begun to link ozone removal with physical characteristics such as porosity and surface area [51].

Control of VOCs via surface chemistry has also been of rising interest, especially using photocatalytic materials such as $\mathrm{TiO}_{2}$. Salthammer and Fuhrmann found that commercially available photocatalytic paints were able to reduce concentrations of formaldehyde and $\mathrm{NO}_{2}$ using sunlight simulating lamps [52]. In field experiments, Auvinen and Wirtanen found that photocatalytic paints can actively convert compounds, but undesirable by-products are formed [53]. Recently, Gandolfo et al. showed that removal of $\mathrm{NO}_{2}$ can be accompanied by formation of $\mathrm{HONO}$, which can initiate undesirable oxidation chemistry upon photolysis of HONO [54]. Advances continue to be made in the performance of photocatalysts under indoor lighting conditions but by-product formation remains a challenge.

\section{The Impact of the Presence of People}

An intriguing area of research has emerged around the idea that occupants influence the ozone chemistry in buildings. Several studies have shown that ozone chemistry taking place on clothing [22, 23, 55], skin [56•], and hair [57] reduce indoor concentrations of ozone and increase gas-phase and aerosol reaction products associated with occupant surface chemistry. Ozone reacts with fatty acids and squalene in human skin oils (sebum) and generates a suite of products such as acetone, nonanal, 4-oxopentanal, and 6-methyl-5-hepten-2-one. In the microenvironment surrounding a person, this chemistry lowers ozone levels and increases product concentrations, thereby influencing inhalation exposure [58]. In recent work with human subjects, Fadeyi et al. showed that occupants in a chamber reduce SOA concentrations that result from limonene-ozone reactions, primarily because they are reducing indoor ozone concentrations by reaction at the skin and clothing surfaces [59].

\section{Health}

Perhaps one of the least well-understood, but vital, issues is the impact of indoor chemistry on human health. The formation of by-products from the reaction of ozone with terpenes has prompted a number of in vitro, animal, and human studies. For an excellent recent discussion of health studies related to ozone-terpene chemistry, please see Rohr's review [60]. Early mouse studies of reactions of ozone $\alpha$-pinene [61] and dlimonene [62] suggested that products acted as airway irritants. Some multifunctional compounds such as dicarbonyls 
[63] and gas-phase biradicals [64] have been suggested as being responsible.

Peroxides formed are also of concern as they constitute "reactive oxygen species" or ROS that may result in more chronic health problems. ROS is linked to oxidative stress which may lead to pulmonary diseases and cancer. Anderson et al. [65] found that cell proliferation decreased in epithelial cells (in vitro) when exposed to limonene-ozone mixtures that were at a high concentration relative to typical indoor environments. They inferred that products of the ozonation chemistry were responsible. Fadeyi et al. exposed asthmatics and non-asthmatics to either clean air or air with limonene-ozone (and their respective reaction products) and studied perception, work performance, and physiological characteristics [59]. They found that the level of $\alpha$-amylase (a stress indicator) in saliva increased with exposure to the limonene-ozone mixture. Chen and Hopke [66-68] studied the SOA and ROS generated by the reactions of ozone with $\alpha$-pinene and limonene. They found quantifiable levels of ROS, measured as the hydrogen peroxide equivalent, suggesting that this chemistry could have adverse health endpoints. Kurshid et al. measured ROS, such as peroxides, in aerosols in 12 residential and 11 commercial and retail buildings [69]. They found that the indoor concentration of ROS was similar to that outdoors and that there were no clear associations with other measured species (PM, VOCs, ozone). They recommended that ROS be measured independently, as its concentration cannot yet be inferred from other species.

\section{Conclusions}

This research field is still very young and there are many opportunities for discovery. The following are just a few areas that have been noted by others or are of particular interest.

- Most indoor air chemistry models include surface chemistry in the form of deposition and subsequent removal of compounds or aerosols. Although some information exists on the yield of some products from ozonation at surfaces such as carpet, paint, or clothing, models do not include explicit mechanistic predictions of the chemistry or kinetics necessary to predict formation of new products at the surface. Indoor surfaces are highly heterogeneous and a deep understanding of their composition and local environmental conditions will be necessary to make such predictions. A better understanding of local adsorption phenomena will also be helped by improved surface composition information: note that sorption of basic amines such as nicotine is sensitive to humidity, $\mathrm{CO}_{2}$, and ammonia [70]. It is likely that this is also true for organic acids and other species that undergo acid-base chemistry.
- There has been growing interest in using advanced analytical techniques, originally designed for outdoor atmospheric chemistry research, to study indoor environments. Examples include proton-transfer chemical-ionization mass spectrometry (PTRMS) [55] to obtain real-time concentrations of VOC reaction products, light-induced fluorescence-fluorescence assay by gas expansion (LIFFAGE) [38•] for direct measurement of $\mathrm{OH}$ and $\mathrm{HO}_{2}$ radicals, and cavity ring-down spectroscopy for measurement of the nitrate radical [71]. There are many more opportunities to advance this field using wellestablished instrumentation and more recent innovative instruments.

- Recent observations of high $\mathrm{OH}$ concentrations indoors, possibly related to photolysis of HONO, have suggested more detailed studies of the spectral intensity due to sunlight penetration through windows, changes in window glazing, and a changing landscape of indoor lighting (CFL, incandescent, LED) [72].

- MacLean et al. found that lead in house dust weathers to become more bioavailable over several months of exposure to typical temperature and humidity [73]. How does such aging under the unique conditions in buildings influence the bioavailability of other metals tracked in on shoes or deposited from outdoor air ventilation?

- Buildings that have excessive mold growth and been contaminated with pathogenic organisms or toxic chemicals can be decontaminated in many ways, with uncertain chemical outcomes. For example, Corsi and Poppendieck investigated the use of very high levels of ozone and chlorine dioxide as a disinfectant and observed persistent emissions of carbonyl compounds, and even chlorinated by-products, long after the ozonation event [74, 75]. Ozone and $\mathrm{ClO}_{2}$ continue to be promoted for disinfection without sufficient follow-up on the impact on indoor air quality of such methods.

- Microorganisms in buildings also are responsible for changing indoor environments, including the chemicals present. There has been a surge of interest in understanding the indoor microbiome [76]. These organisms grow, respire, and can release the by-products of their biochemistry into the indoor environment. For example, Inamdar et al. showed that a 1-octen-3-ol, a "mushroom alcohol" generated by indoor fungi, reduced uptake of dopamine in human cell lines and suggests that it could represent an environmental agent involved in Parkinson's disease [77].

This review has touched on much of the existing information on indoor chemistry as it relates to air quality, but is necessarily of limited scope. Future reviews of indoor chemistry will likely need to focus on specific topics within this field to synthesize the material in a substantive fashion. I look 
forward to those reviews and the new discoveries in this rapidly growing research field.

\section{Compliance with Ethics Guidelines}

Conflict of Interest Glenn Morrison declares that he has no conflict of interest.

Human and Animal Rights and Informed Consent This article does not contain any studies with human or animal subjects performed by any of the authors.

\section{References}

Papers of particular interest, published recently, have been highlighted as:

- Of importance

1. Weschler CJ. Chemistry in indoor environments: 20 years of research. Indoor Air. 2011;21:205-18.

2. Nazaroff WW, Cass GR. Mathematical modeling of chemically reactive pollutants in indoor air. Environ Sci Technol. 1986;20: 924-34.

3. Weschler CJ, Shields HC. Indoor ozone/terpene reactions as a source of indoor particles. Atmos Environ. 1999;33:2301-12.

4. Hodgson AT, Beal D, Mcllvaine JER. Sources of formaldehyde, other aldehydes and terpenes in a new manufactured house. Indoor Air. 2002;12:235-42.

5. Hodgson AT, Levin H. Volatile organic compounds in indoor air: a review of concentrations measured in North America since 1990. Berkeley, California: Lawrence Berkeley National Laboratory; 2003. Report No.: LBNL-51715.

6. Nazaroff WW, Weschler CJ. Cleaning products and air fresheners: exposure to primary and secondary air pollutants. Atmos Environ. 2004;38:2841-65.

7. Wells JR. Gas-phase chemistry of alpha-terpineol with ozone and $\mathrm{OH}$ radical: rate constants and products. Environ Sci Technol. 2005;39:6937-43.

8. Sarwar G, Olson DA, Corsi RL, Weschler CJ. Indoor fine particles: the role of terpene emissions from consumer products. J Air Waste Manag Assoc. 2004;54:367-77.

9. Destaillats H, Lunden MM, Singer BC, Coleman BK, Hodgson AT, Weschler CJ, et al. Indoor secondary pollutants from household product emissions in the presence of ozone. A bench-scale chamber study. Environ Sci Technol. 2006;40:4421-8.

10. Rossignol S, Rio C, Ustache A, Fable S, Nicolle J, Même A, et al. The use of a housecleaning product in an indoor environment leading to oxygenated polar compounds and SOA formation: gas and particulate phase chemical characterization. Atmos Environ. 2013;75:196-205.

11. Carslaw N. A new detailed chemical model for indoor air pollution. Atmos Environ. 2007;41:1164-79.

12. Carslaw N, Mota T, Jenkin ME, Barley MH, McFiggans G. A significant role for nitrate and peroxide groups on indoor secondary organic aerosol. Environ Sci Technol. 2012;46:9290-8. Suggests that a significant fraction of aerosols formed indoors are comprised of peroxides and organic nitrates.

13. Carslaw N. A mechanistic study of limonene oxidation products and pathways following cleaning activities. Atmos Environ. 2013;80:507-13.
14. Youssefi S, Waring MS. Predicting secondary organic aerosol formation from terpenoid ozonolysis with varying yields in indoor environments. Indoor Air. 2012;22:415-26.

15. Jonsson ÅM, Hallquist M, Ljungström E. Impact of humidity on the ozone initiated oxidation of limonene, $\Delta 3$-carene, and $\alpha$-pinene. Environ Sci Technol. 2006;40:188-94.

16. Norgaard AW, Nojgaard JK, Larsen K, Sporring S, Wilkins CK, Clausen PA, et al. Secondary limonene endo-ozonide: a major product from gas-phase ozonolysis of R-(+)-limonene at ambient temperature. Atmos Environ. 2006;40:3460-6.

17. Waring MS, Wells JR, Siegel JA. Secondary organic aerosol formation from ozone reactions with single terpenoids and terpenoid mixtures. Atmos Environ. 2011;45:4235-42.

18. Pathak RK, Salo K, Emanuelsson EU, Cai C, Lutz A, Hallquist $\AA \mathrm{M}$, et al. Influence of ozone and radical chemistry on limonene organic aerosol production and thermal characteristics. Environ Sci Technol. 2012;46:11660-9.

19. Huang Y, Lee SC, Ho KF, Ho SSH, Cao N, Cheng Y, et al. Effect of ammonia on ozone-initiated formation of indoor secondary products with emissions from cleaning products. Atmos Environ. 2012;59:224-31.

20. Forester CD, Wells JR. Hydroxyl radical yields from reactions of terpene mixtures with ozone. Indoor Air. 2011;21:400-9.

21. Morrison G. Interfacial chemistry in indoor environments. Environ Sci Technol. 2008;42:3495-9.

22. Coleman BK, Destaillats H, Hodgson AT, Nazaroff WW. Ozone consumption and volatile byproduct formation from surface reactions with aircraft cabin materials and clothing fabrics. Atmos Environ. 2008;42:642-54.

23. Rai AC, Guo B, Lin C-H, Zhang J, Pei J, Chen Q. Ozone reaction with clothing and its initiated VOC emissions in an environmental chamber. Indoor Air. 2014;24:49-58.

24. Kwamena N-OA, Thornton JA, Abbatt JPD. Kinetics of surfacebound benzo[a]pyrene and ozone on solid organic and salt aerosols. J Phys Chem A. 2004;108:11626-34.

25. Springs M, Wells J, Morrison G. Reaction rates of ozone and terpenes adsorbed to model indoor surfaces. Indoor Air. 2011;21:319 27.

26. Shu S, Morrison GC. Surface reaction rate and probability of ozone and alpha-terpineol on glass, polyvinyl chloride, and latex paint surfaces. Environ Sci Technol. 2011;45:4285-92.

27. Shu S, Morrison GC. Rate and reaction probability of the surface reaction between ozone and dihydromyrcenol measured in a bench scale reactor and a room-sized chamber. Atmos Environ. 2012;47: 421-7.

28. Ham JE, Wells JR. Surface chemistry reactions of alpha-terpineol [(R)-2-(4-methyl-3-cyclohexenyl)isopropanol] with ozone and air on a glass and a vinyl tile. Indoor Air. 2008;18:394-407.

29. Petrick LM, Sleiman M, Dubowski Y, Gundel LA, Destaillats H. Tobacco smoke aging in the presence of ozone: a room-sized chamber study. Atmos Environ. 2011;45:4959-65.

30. Sleiman M, Gundel LA, Pankow JF, Jacob III P, Singer BC, Destaillats H. Formation of carcinogens indoors by surfacemediated reactions of nicotine with nitrous acid, leading to potential thirdhand smoke hazards. Proc Natl Acad Sci U S A. 2010;107: 6576-81. First evidence of nitrosamines generated when HONO reacts with nicotine on surfaces.

31. Wang $C$, Waring MS. Secondary organic aerosol formation initiated from reactions between ozone and surface-sorbed squalene. Atmos Environ. 2014;84:222-9.

32. Waring MS, Siegel JA. Indoor secondary organic aerosol formation initiated from reactions between ozone and surface-sorbed d-limonene. Environ Sci Technol. 2013;47:6341-8.

33. Petrick LM, Svidovsky A, Dubowski Y. Thirdhand smoke: heterogeneous oxidation of nicotine and secondary aerosol formation in the indoor environment. Environ Sci Technol. 2011;45:328-33. 
34. Rai AC, Guo B, Lin C-H, Zhang J, Pei J, Chen Q. Ozone reaction with clothing and its initiated particle generation in an environmental chamber. Atmos Environ. 2013;77:885-92.

35. Beko G, Clausen G, Weschler CJ. Further studies of oxidation processes on filter surfaces: evidence for oxidation products and the influence of time in service. Atmos Environ. 2007;41:5202-12.

36. Reche C, Viana M, Rivas I, Bouso L, Àlvarez-Pedrerol M, Alastuey A, et al. Outdoor and indoor UFP in primary schools across Barcelona. Sci Total Environ. 2014;493:943-53.

37. Pitts Jr JN, Wallington TJ, Biermann HW, Winer AM. Identification and measurement of nitrous acid in an indoor environment. Atmos Environ Part Gen Top. 1985;19:763-7.

38. Gómez Alvarez E, Amedro D, Afif C, Gligorovski S, Schoemaecker C, Fittschen C, et al. Unexpectedly high indoor hydroxyl radical concentrations associated with nitrous acid. Proc Natl Acad Sci. 2013;110:13294-9. First experimental evidence that HONO increases indoor $\mathrm{OH}$ radical concentrations well beyond that anticipated by current models.

39. Gómez Alvarez E, Sörgel M, Gligorovski S, Bassil S, Bartolomei $\mathrm{V}$, Coulomb B, et al. Light-induced nitrous acid (HONO) production from NO2 heterogeneous reactions on household chemicals. Atmos Environ. 2014;95:391-9.

40. Bartolomei V, Sörgel M, Gligorovski S, Alvarez EG, Gandolfo A, Strekowski R, et al. Formation of indoor nitrous acid (HONO) by light-induced $\mathrm{NO} 2$ heterogeneous reactions with white wall paint. Environ Sci Pollut Res. 2014;21:9259-69.

41. Weschler CJ, Shields HC. Experiments probing the influence of air exchange rates on secondary organic aerosols derived from indoor air chemistry. Atmos Environ. 2003;37:5621-31.

42. Waring MS, Siegel JA. The influence of HVAC systems on indoor secondary organic aerosol formation. 2010. p. 556-71. Available from: http://www.scopus.com/inward/record.url?eid=2-s2.0$77954253073 \&$ p a r tn e r I D $=40 \&$ m d $5=$ 1324a57bdd7d6acd6db4531fdaad6e 40

43. Fadeyi MO. Mass balance modeling of building recirculation rates and filtration efficiencies effects on secondary organic aerosols derived from ozone-initiated chemistry. Build Simul. 2014;7:165-73.

44. Waring MS, Siegel JA. The effect of an ion generator on indoor air quality in a residential room. Indoor Air. 2011;21:267-76.

45. Gall ET, Corsi RL, Siegel JA. Barriers and opportunities for passive removal of indoor ozone. Atmos Environ. 2011;45:3338-41.

46. Kunkel DA, Gall ET, Siegel JA, Novoselac A, Morrison GC, Corsi RL. Passive reduction of human exposure to indoor ozone. Build Environ. 2010;45:445-52.

47. Hoang CP, Kinney KA, Corsi RL. Ozone removal by green building materials. Build Environ. 2009;44:1627-33.

48. Lamble SP, Corsi RL, Morrison GC. Ozone deposition velocities, reaction probabilities and product yields for green building materials. Atmos Environ. 2011;45:6965-72.

49. Cros CJ, Morrison GC, Siegel JA, Corsi RL. Long-term performance of passive materials for removal of ozone from indoor air. Indoor Air. 2012;22:43-53.

50. Darling EK, Cros CJ, Wargocki P, Kolarik J, Morrison GC, Corsi RL. Impacts of a clay plaster on indoor air quality assessed using chemical and sensory measurements. Build Environ. 2012;57:370 6.

51. Gall ET, Corsi RL, Siegel JA. Impact of physical properties on ozone removal by several porous materials. Environ Sci Technol. 2014;48:3682-90.

52. Salthammer T, Fuhrmann F. Photocatalytic surface reactions on indoor wall paint. Environ Sci Technol. 2007;41:6573-8.

53. Auvinen J, Wirtanen L. The influence of photocatalytic interior paints on indoor air quality. Atmos Environ. 2008;42:4101-12.

54. Gandolfo A, Bartolomei V, Gomez Alvarez E, Tlili S, Gligorovski $\mathrm{S}$, Kleffmann J, et al. The effectiveness of indoor photocatalytic paints on NOx and HONO levels. Appl Catal B Environ. 2015;166-167:84-90.

55. Wisthaler A, Tamas G, Wyon DP, Strom-Tejsen P, Space D, Beauchamp J, et al. Products of ozone-initiated chemistry in a simulated aircraft environment. Environ Sci Technol. 2005;39:482332.

56. Wisthaler A, Weschler CJ. Reactions of ozone with human skin lipids: sources of carbonyls, dicarbonyls, and hydroxycarbonyls in indoor air. Proc Natl Acad Sci U S A. 2010;107:6568-75. Direct evidence of ozone forming important multifunctionalized VOCs on human skin.

57. Pandrangi LS, Morrison GC. Ozone interactions with human hair: ozone uptake rates and product formation. Atmos Environ. 2008;42:5079-89.

58. Rim D, Novoselec A, Morrison G. The influence of chemical interactions at the human surface on breathing zone levels of reactants and products. Indoor Air. 2009;19:324-34.

59. Fadeyi MO, Weschler CJ, Tham KW, Wu WY, Sultan ZM. Impact of human presence on secondary organic aerosols derived from ozone-initiated chemistry in a simulated office environment. Environ Sci Technol. 2013;47:3933-41.

60. Rohr AC. The health significance of gas- and particle-phase terpene oxidation products: a review. Environ Int. 2013;60:145-62.

61. Wolkoff P, Clausen PA, Wilkins CK, Hougaard KS, Nielsen GD. Formation of strong airway irritants in a model mixture of (+)-alpha-pinene/ozone. Atmos Environ. 1999;33:693-8.

62. Clausen PA, Wilkins CK, Wolkoff P, Nielsen GD. Chemical and biological evaluation of a reaction mixture of R-(+)-limonene/ ozone-formation of strong airway irritants. Environ Int. 2001;26:511-22.

63. Anderson SE, Franko J, Jackson LG, Wells JR, Ham JE, Meade BJ. Irritancy and allergic responses induced by exposure to the indoor air chemical 4-oxopentanal. Toxicol Sci. 2012;127:371-81.

64. Vibenholt A, Nørgaard AW, Clausen PA, Wolkoff P. Formation and stability of secondary ozonides from monoterpenes studied by mass spectrometry. Chemosphere [Internet]. In Press, Corrected Proof. Available from: http:/www.sciencedirect.com/science/article/ B6V74-4VY167H-3/2/ae780f2814c89778947e40d494127825.

65. Anderson SE, Khurshid SS, Meade BJ, Lukomska E, Wells JR. Toxicological analysis of limonene reaction products using an in vitro exposure system. Toxicol In Vitro. 2013;27:721-30.

66. Chen X, Hopke PK. A chamber study of secondary organic aerosol formation by linalool ozonolysis. Atmos Environ. 2009;43:393540.

67. Chen X, Hopke PK, Carter WPL. Secondary organic aerosol from ozonolysis of biogenic volatile organic compounds: chamber studies of particle and reactive oxygen species formation. Environ Sci Technol. 2011;45:276-82.

68. Chen X, Hopke PK. A chamber study of secondary organic aerosol formation by limonene ozonolysis. Indoor Air. 2010;20:320-8.

69. Khurshid SS, Siegel JA, Kinney KA. Indoor particulate reactive oxygen species concentrations. Environ Res. 2014;132:46-53.

70. Ongwandee M, Sawanyapanich P. Influence of relative humidity and gaseous ammonia on the nicotine sorption to indoor materials. Indoor Air. 2012;22:54-63.

71. Flemmer MM, Ham JE. Cavity ring-down spectroscopy with an automated control feedback system for investigating nitrate radical surface chemistry reactions. Rev Sci Instrum [Internet]. 2012;83. Available from: http://www.scopus.com/inward/record.url?eid=2s $2.0-84865791620 \&$ p artner I D $=40 \&$ m d $5=$ d0d73989202d8154cc99fc4e6dae3842

72. Gligorovski S, Weschler CJ. The oxidative capacity of indoor atmospheres. Environ Sci Technol. 2013;47:13905-6.

73. MacLean LCW, Beauchemin S, Rasmussen PE. Chemical transformations of lead compounds under humid conditions: implications for bioaccessibility. Environ Geochem Health. 2013;35:153-9. 
74. Poppendieck DG, Hubbard HF, Weschler CJ, Corsi RL. Formation and emissions of carbonyls during and following gas-phase ozonation of indoor materials. Atmos Environ. 2007;41:7614-26.

75. Corsi RL, Hubbard H, Poppendieck D, Ward M, Weschler CJ. Chlorine dioxide as a building disinfectant: surface consumption and by-product generation. 2006. p. 115-20. Available from: http://www.scopus.com/inward/record.url? eid=2-s2.0-
$84871592748 \&$ p a r t n e r I D $=40 \&$ m d $5=$ flb676dd99abb9e2aa0455209c229f0e.

76. Konya T, Scott JA. Recent advances in the microbiology of the built environment. Curr Sustain Renew Energy Rep. 2014;1:35-42.

77. Inamdar AA, Hossain MM, Bernstein AI, Miller GW, Richardson JR, Bennett JW. Fungal-derived semiochemical 1-octen-3-ol disrupts dopamine packaging and causes neurodegeneration. Proc Natl Acad Sci. 2013;110:19561-6. 